\title{
Dynamic Deformation Behaviour of Chiral Auxetic Lattices at Low and High Strain-Rates
}

\author{
Anja Mauko ${ }^{1, *}$, Tomáš Fíla ${ }^{2}$, Jan Falta ${ }^{2}$, , Petr Koudelka ${ }^{2}$, Václav Rada ${ }^{2}$, Michaela Neuhäuserová $^{2}$, \\ Petr Zlámal ${ }^{2}$, Matej Vesenjak ${ }^{1}(\mathbb{D})$, Ondřej Jiroušek ${ }^{2}$ (D) and Zoran Ren ${ }^{1}$ (D) \\ 1 Faculty of Mechanical Engineering, University of Maribor, Smetanova ul. 17, 2000 Maribor, Slovenia; \\ matej.vesenjak@um.si (M.V.); zoran.ren@um.si (Z.R.) \\ 2 Department of Mechanics and Materials, Faculty of Transportation Sciences, Czech Technical University in \\ Prague, Konviktská 20, 11000 Prague, Czech Republic; fila@fd.cvut.cz (T.F.); faltaja2@fd.cvut.cz (J.F.); \\ koudelka@fd.cvut.cz (P.K.); rada@fd.cvut.cz (V.R.); neuhauserova@fd.cvut.cz (M.N.); zlamal@fd.cvut.cz (P.Z.); \\ jirousek@fd.cvut.cz (O.J.) \\ * Correspondence: anja.mauko@um.si; Tel.: +386-2-220-7698
}

check for updates

Citation: Mauko, A.; Fíla, T.; Falta, J.; Koudelka, P.; Rada, V.; Neuhäuserová, M.; Zlámal, P.; Vesenjak, M.; Jiroušek, O.; Ren, Z. Dynamic Deformation Behaviour of Chiral Auxetic Lattices at Low and High Strain-Rates. Metals 2021, 11, 52. https://doi.org/

10.3390/met11010052

Received: 30 November 2020 Accepted: 22 December 2020 Published: 29 December 2020

Publisher's Note: MDPI stays neutral with regard to jurisdictional claims in published maps and institutional affiliations.

Copyright: () 2020 by the authors. Licensee MDPI, Basel, Switzerland. This article is an open access article distributed under the terms and conditions of the Creative Commons Attribution (CC BY) license (https: / / creativecommons.org/ licenses/by/4.0/).

\begin{abstract}
The mechanical behaviour of three different auxetic cellular structures, hexa-chiral 2D, tetra-chiral 2D and tetra-chiral 3D, was experimentally investigated in this study. The structures were produced with the powder bed fusion method (PBF) from an austenitic stainless steel alloy. The fundamental material mechanical properties of the sample structures were determined with classic quasi-static compressive tests, where the deformation process was captured by a high-resolution digital camera. The Split Hopkinson Pressure Bar (SHPB) apparatus was used for dynamic impact testing at two impact velocities to study the strain-rate dependency of the structures. Two synchronised high-speed cameras were used to observe the impact tests. The captured images from both quasi-static and dynamic experiments were processed using a custom digital image correlation (DIC) algorithm to evaluate the displacement/strain fields and the Poisson's ratio. Predominant auxetic behaviour was observed in all three structures throughout most of the deformation process both under quasi-static and impact loading regimes. The tetra-chiral 2D structure showed the most significant auxetic behaviour. Significant stress enhancement in all tested structures was observed in dynamic testing. The Poisson's ratio strain-rate dependency was confirmed for all three auxetic structures.
\end{abstract}

Keywords: auxetic chiral structures; Split Hopkinson Pressure Bar; low and high strain rates; digital image correlation; mechanical behaviour; strain rate sensitivity

\section{Introduction}

There is an ever-increasing interest in the mechanical characterisation of cellular structures [1-3] for their use in modern, low-weight engineering structures. Auxetic structures are particular types of cellular structures exhibiting negative Poisson's ratio, i.e., the structure contracts in a lateral direction under compressive loading or expands under tensile loading [4]. A few auxetic structures have been designed [5] and studied so far [6-8], such as chiral structures where material nodes are interconnected by ligament connections [9]. Chiral structures have some remarkable properties, such as anisotropy [10], and are frequently used as fillers of hollow solids [11-13].

Cellular materials usually have increased mechanical energy absorption properties due to extensive elastoplastic deformation of their internal structure, which is often characterised by long stress plateau at increasing strain [14,15]. Auxetic chiral cellular structures can exhibit even higher energy absorption due to predominant ligament bending deformation $[12,16]$. However, the response of the cellular structures can be strain-rate dependent, which also necessitates the characterisation of their dynamic properties. Previous studies have shown a non-strain-rate dependency of some chiral structures with low stiffness [17], while the other study demonstrated stress enhancement of auxetic re-entrant honeycomb 
lattices at the transitional loading rate [18]. This indicates the need for further investigations of possible strain-rate dependency of chiral auxetic structures.

The Split Hopkinson Pressure Bar (SHPB) apparatus is a widely used testing device for characterisation of material dynamic mechanical properties of homogeneous materials at high strain-rates [19]. However, the SHPB methodology can also be adapted for testing cellular materials $[20,21]$ with some dimensional constraints on the representative volume element (RVE) size of samples [19].

This study investigates three different chiral structures, the hexa-chiral 2D, the tetrachiral 2D and the tetra-chiral 3D structures, produced with the powder bed fusion (PBF) method from an austenitic stainless steel alloy [22]. The fundamental material mechanical properties of sample structures were determined with classic quasi-static compressive tests. Dynamic impact experiments were conducted on SHPB at two impact velocities to study the strain-rate dependency of the structures. A pair of high-speed cameras were used to record the deformation behaviour for the follow-on digital image correlation (DIC) evaluation of Poisson's ratio, deformation and strain fields.

\section{Materials}

Samples Preparation and Fabrication of Auxetic Structures

All samples were manufactured with a PBF method on the AM250 additive manufacturing device (Renishaw, Wotton-under-Edge, United Kingdom) from austenitic stainless steel alloy (SS 316L-0407) with the base material density $\rho_{0}=7990 \mathrm{~kg} / \mathrm{m}^{3}$ and the yield strength of $494 \mathrm{MPa}$ (Figure 1). Powdered stainless steel 316L-0407 with granularity in the range of $15-45 \mu \mathrm{m}$ was layered in $50 \mu \mathrm{m}$ thick layers and melted with a laser beam with a maximal power of $200 \mathrm{~W}$ during the production process. The detailed composition of the material is given in Table 1. The dimensions of the samples (Table 2) were determined regarding geometric constraints of the impact testing apparatus. The specimens consisted of a minimum of five cells in a longitudinal and lateral direction to obtain appropriate RVE [23]. The relative density of the samples was determined as $\rho_{r}=\rho / \rho_{0}$, where $\rho$ and $\rho_{0}$ represent bulk specimen density and density of the base material, respectively. Porosity $p$ of the specimens was calculated as $p=1-\rho_{r}$.

(a)
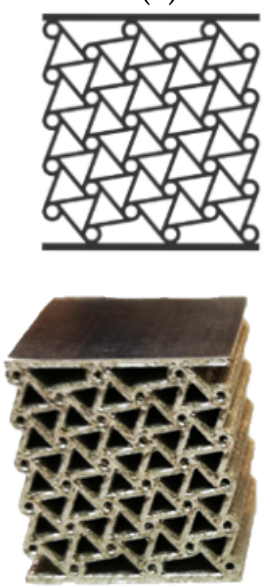

(b)
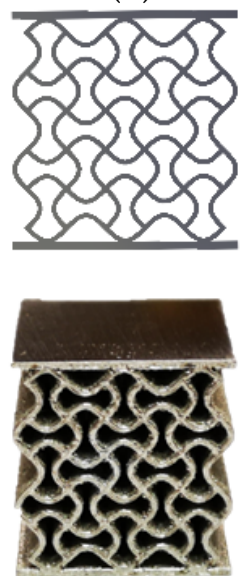

(c)
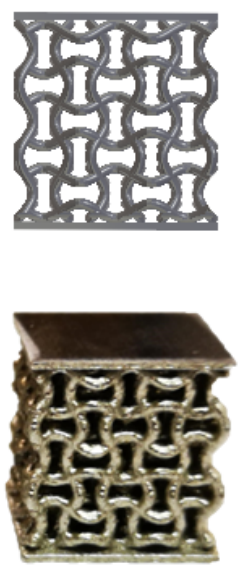

Figure 1. Visualisation of analysed geometries (first row) and image of tested specimens (second row), (a) hexa-chiral 2D, (b) tetra-chiral 2D, and (c) tetra-chiral structure 3D.

Table 1. Mass composition of elements of austenitic stainless steel alloy (SS 316L-0407).

\begin{tabular}{cccccccc}
\hline Element & Iron & Chromium & Nickel & Molybdenum & Manganese & Silicon & Other Elements \\
\hline Mass $(\%)$ & balance & $16-18$ & $10-14$ & $2-3$ & $\leq 2$ & $\leq 1$ & $\leq 0.1$ \\
\hline
\end{tabular}


Table 2. Dimensions and material parameters of specimens.

\begin{tabular}{cccccc}
\hline Structure & $\begin{array}{c}\text { Specimen } \\
\text { Dimension }(\mathbf{m m})\end{array}$ & $\begin{array}{c}\text { Nominal Strut } \\
\text { Thickness }(\mathbf{m m})\end{array}$ & Relative Density $\boldsymbol{\rho}_{\boldsymbol{r}}$ & Porosity $\boldsymbol{\varphi}$ & $\begin{array}{c}\text { Number of } \\
\text { Specimens }\end{array}$ \\
\hline hexa-chiral 2D & $14.0 \times 14.0 \times 14.0$ & 0.3 & 0.5 & 0.5 & 13 \\
tetra-chiral 2D & $14.5 \times 14.5 \times 14.5$ & 0.3 & 0.39 & 0.61 & 13 \\
tetra-chiral 3D & $13.0 \times 13.0 \times 13.0$ & 0.68 & 0.37 & 0.63 & 13 \\
\hline
\end{tabular}

Additional impact plates were added to the top and bottom of the specimens to enable proper positioning of the specimens between impact faces in the SHPB test apparatus. The additional plates represent homogeneous parts of the specimen, such as the solid frame, and can affect the response of the cellular structure. The plates outer surfaces were carefully treated by fine brushing to prevent samples sliding between the impact bars. Also, a thin layer of paint coat was applied on one side of each sample to create a random pattern of speckle for better performance of full-field displacement correlation during DIC analysis of high-speed camera recordings.

\section{Methods}

\subsection{Quasi-Static Testing}

An electro-mechanic testing device (INSTRON 3382, Instron [24], Norwood, MA, USA) with a maximum loading capacity of $100 \mathrm{kN}$ was used for quasi-static uniaxial compressive testing of the samples. The position controlled cross-head loading rate was set to $2 \mathrm{~mm} / \mathrm{min}$ with a maximum displacement of $13 \mathrm{~mm}$. The applied force and deformation were measured with $10 \mathrm{~Hz}$ frequency during the testing. All tests were observed with a high-resolution digital camera (Manta G-504B, AVT, München, Germany) equipped with a bi-telecentric zoom lens (TCZR072, Opto Engineering) for further post-processing of the data with DIC method. The imaging was performed with a resolution of $2452 \mathrm{px} \times 2056 \mathrm{px}$ at $2 \mathrm{fps}$. Each chiral structure was tested with three quasi-static tests on an electro-mechanic testing device with good repeatability of results.

\subsection{Dynamic Testing}

A SHPB apparatus at the Czech Technical University in Prague was used to carry out the dynamic impact testing. The aluminium alloy (EN-AW-7075) incident, transmission and striker bars with the same diameter of $20 \mathrm{~mm}$ were used for the purpose of this study. The length of the incident and the transmission bar was $1600 \mathrm{~mm}$. The length of the striker was $500 \mathrm{~mm}$ and $650 \mathrm{~mm}$. The strikers were accelerated in a $2500 \mathrm{~mm}$ long gas-gun barrel by the fast release of compressed air at a maximum pressure of 16 bar from a $20 \mathrm{~L}$ reservoir. At higher impact velocities, it is necessary to absorb the residual impact energy in the bars to prevent damage of the strain-gauges. This is usually done by hydraulic dampers. However, the reaction forces in the used hydraulic damper in this study exceeded their design limit. Additional aluminium rods and wood dowel rods were added as absorbers.

The axial and horizontal alignment of the bars to achieve quasi-one-dimensional wave propagation in the bars and to minimise friction in bar supports was accomplished with the use of two lasers [25]. All bar surfaces were carefully polished, especially the impact faces.

Foil strain-gauges (3/120 LY61, HBM, Darmstadt, Germany) with an active length of $3 \mathrm{~mm}$ and resistance of $120 \Omega$ have been used for strain measurements on the SHPB testing devices. The gauges were positioned in the middle of the incident and the transmission bars ( $800 \mathrm{~mm}$ from the bar ends) at two measuring points. The half Wheatstone bridge circuit arrangement of strain-gauges was selected to cancel the negative potential bending effect of the bars. Strain-gauges were connected to the power supply unit with a constant voltage of $4 \mathrm{~V}$. A differential low noise amplifier (EL-LNA-2, Elsys AG, Niederrohrdorf, Switzerland) was used to amplify the low signal from the strain-gauge bridges with a gain of 100. A 16-bit digitiser (PCI-9826H, ADLINK Technology, Tajpej, Taiwan) with a maximum sampling rate of $20 \mathrm{MHz}$ was employed to record the output voltage history. 
Laser photoelectric sensors (FS/FE 10-RL-PS-E4, Sensopart, Gottenheim, Germany) were placed at the end of the acceleration barrel to measure the striker velocity and to trigger the high-speed camera and strain-gauge measurements. Two high-speed digital cameras (FASTCAM SA-Z, Photron, Tokyo, Japan) were used in all the experiments to capture the deformation behaviour of the samples and to provide data for further DIC evaluation. The first camera was set to record at $252 \mathrm{kfps}$ and an image resolution of $256 \mathrm{px} \times 168 \mathrm{px}$. The second camera was added for the purpose of visual inspection of the samples and the SHPB set-up during the experiment and was placed on the opposite side of the first camera and set to record at $280 \mathrm{kfps}$ and image resolution of $256 \mathrm{px} \times 144 \mathrm{px}$. A pair of high-power LED lights (Multiled QT, GS Vitec, Bad Soden-Salmünster, Germany) was used for appropriate illumination of the samples. Two paper strips with random black speckle patterns were placed at each side of samples on the bar impact ends to provide for reference positions in the subsequent DIC evaluation of high-speed recordings.

The SHPB set-up was appropriately calibrated with force calibration and void validation tests prior to testing of the auxetic structures. Correct alignment of the bars was confirmed with a dynamic force equilibration test (Figure 2a), where excellent correlation of forces in incident and transmission bars was observed. Two types of void tests were performed, with and without pulse shaper (Figure $2 b, c)$. A smooth propagation and transmission of the deformation waves were observed in both cases, again confirming the validity of the used SHPB set-up.

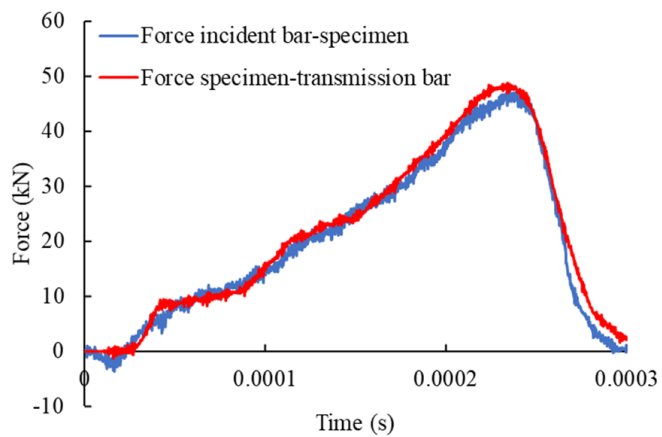

(a)

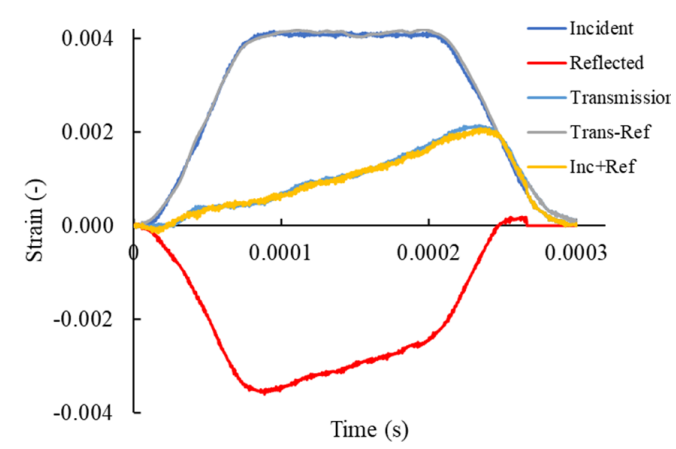

(b)

(c)

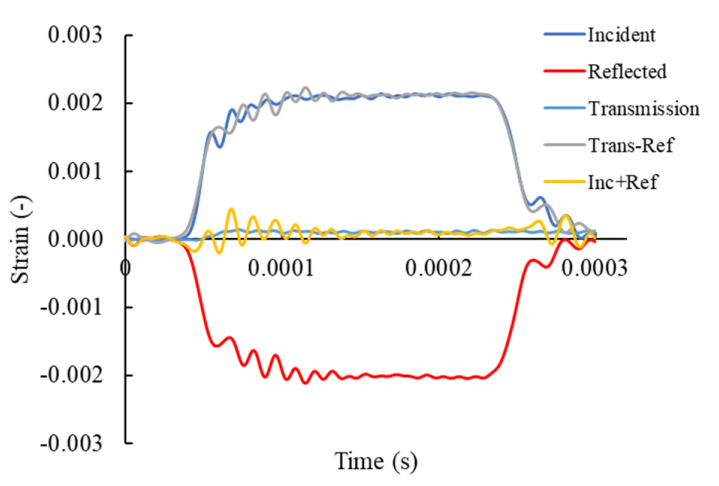

Figure 2. An example of (a) dynamic force equilibration, (b) strain equilibration with pulse shaper, and (c) strain equilibrium without pulse shaper.

A copper pulse shaper was added to the striker's impact face of the incident bar. During the striker's impact on the incident bar, the pulse shaper deforms plastically and serves as an effective filter of the high frequency oscillations in the bars (Figure 2c). Moreover, it prolongs the ramp-in period of the incident wave that positively affects the time to reach the dynamic equilibrium. Desired impact velocities and thus impact energies were achieved by selecting appropriate striker length and acceleration pressure. Each chiral auxetic structure was tested at lower (D1) and higher (D2) impact velocity to observe their 
strain-rate sensitivity, with relevant test data listed in Table 3. Thirty dynamic experiments were conducted in total, i.e., five samples of each structure were tested at two impact velocities.

Table 3. The average dynamic impact testing data.

\begin{tabular}{|c|c|c|c|c|c|c|c|c|}
\hline \multirow[b]{2}{*}{ - } & \multicolumn{4}{|c|}{ Lower Impact Velocity D1 } & \multicolumn{4}{|c|}{ Higher Impact Velocity D2 } \\
\hline & $\begin{array}{c}\text { Striker } \\
\text { Length }(\mathrm{mm})\end{array}$ & Pressure (Bar) & $\begin{array}{c}\text { Striker } \\
\text { Velocity }(\mathrm{m} / \mathrm{s})\end{array}$ & $\begin{array}{c}\text { Max. Strain } \\
\text { Rate }\left(s^{-1}\right)\end{array}$ & $\begin{array}{c}\text { Striker } \\
\text { Length (mm) }\end{array}$ & Pressure (Bar) & $\begin{array}{c}\text { Striker } \\
\text { Velocity }(\mathrm{m} / \mathrm{s})\end{array}$ & $\begin{array}{c}\text { Max. Strain } \\
\text { Rate }\left(\mathrm{s}^{-1}\right)\end{array}$ \\
\hline hexa-chiral 2D & 650 & 5.0 & 28.0 & 1163 & 500 & 9.5 & 47.1 & 2462 \\
\hline tetra-chiral 2D & 650 & 3.0 & 21.8 & 1273 & 500 & 7.0 & 40.9 & 2544 \\
\hline tetra-chiral 3D & 650 & 3.0 & 21.5 & 1287 & 500 & 7.0 & 40.3 & 2706 \\
\hline
\end{tabular}

\subsection{Digital Image Correlation}

The evaluation and validation of the SHPB experimental results were performed with a DIC method. The DIC method is based on tracking of characteristic specimen points in the sequence of images, which captures the deformation process of the observed surface [26]. The DIC was used to analyse the displacement field, strain field and the Poisson's ratio of samples. The DIC was used in two stages: (i) for evaluation of the full-field results or displacements of the individual nodes in the lattice structure during the impact and (ii) to evaluate displacements of the faces of the bars. The obtained results were later compared to results obtained from strain-gauges. The DIC method was in all cases applied with the same parameters to achieve consistency of results. The images were analysed with an in-house open-source algorithm in Matlab [20,27,28] (R2020b, Natick, MA, USA). The high-speed camera recordings of the specimen's deformation process at set fps returned approximately 250 digital frames per specimen test.

\section{Experimental Results}

\subsection{Quasi-Static Results}

Figure 3 shows the average quasi-static compressive behaviour of the tested specimens. The digital images of the sample's deformation sequence were used to calculate the corresponding Poisson's ratios by applying the DIC method. The compression deformation process of chiral auxetic structures can be characterised by three main regions $[6,18,29]$. A stiff, quasi-linear elastic deformation occurs in the first region, which continues until the first structural yielding. The effect of elastoplastic bending and buckling of the cell walls predominates in the second region, which is identified by significantly reduced structural stiffness, resulting in a slow increase or even constant stress (stress plateau) at an increasing strain. Finally, the material undergoes a rapid strengthening due to structural densification until total collapse of the structure.

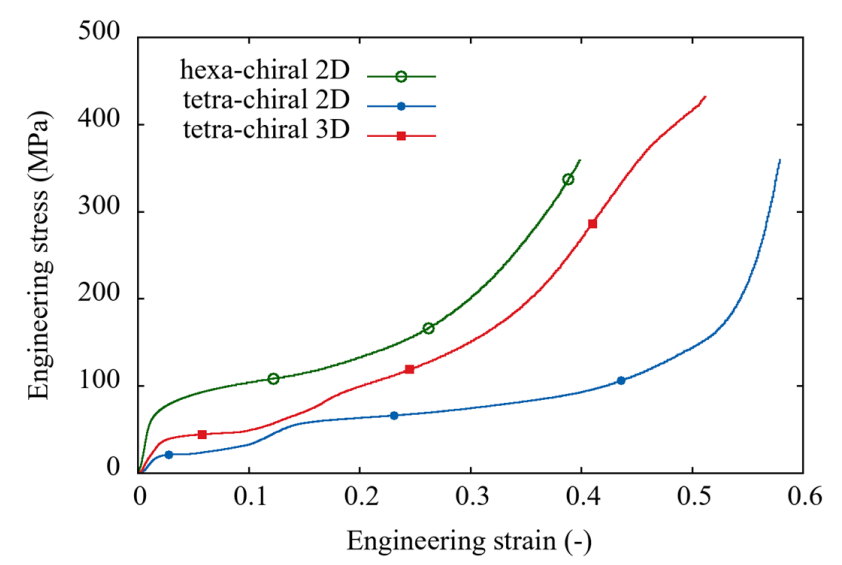

Figure 3. Average quasi-static compression stress-strain curves of hexa-chiral 2D, tetra-chiral 2D and tetra-chiral 3D structure. 


\subsubsection{Hexa-Chiral 2D Structure}

The hexa-chiral 2D structure exhibited the highest overall stiffness of all three tested structures with initial yield stress recorded at $71 \mathrm{MPa}$. The calculated Poisson's ratio rapidly dropped to a maximum negative value at -0.23 at $1.9 \%$ of engineering strain (Figure 4 ). The negative Poisson's value persisted until approximately $37 \%$ of engineering strain and then became positive. The hexa-chiral 2D structure behaved auxetic throughout the whole quasi-plateau region and became almost non-auxetic immediately after the plateau region ended. The lowest auxetic behaviour was observed in the hexa-chiral 2D structure, which inherits almost non-auxetic behaviour after the plateau region. The rotation of cell struts in chiral structures is an important mechanism to induce auxetic behaviour. However, almost no rotation of the cell struts was observed in the hexa-chiral 2D structure during compression testing (Figure 5a). The observed high initial stiffness, followed by almost non-auxetic behaviour, was attributed to the bulky structure of the samples and additional impact plates on the top and bottom of samples, which further prevented the movement of the cells. The reason for the bulkiness of the samples was the small dimensions of the sample and relatively thick cell walls. This problem could be solved by increasing the sample dimensions or reducing the wall thickness. However, the height and width ratio and the RVE had to be considered for valid experimental results, as mentioned in Section 2. Also, the wall thickness was limited by the minimum layer thickness of $0.3 \mathrm{~mm}$ achievable with the used PBF printer.

\subsubsection{Tetra-Chiral 2D Structure}

The tetra-chiral 2D structure returned the lowest yield stress of $19 \mathrm{MPa}$. Interestingly, this structure produced two distinct stress plateau regions. The first plateau occurred immediately after the first structural yielding between $2.2 \%$ and $10.5 \%$ of engineering strain, followed by the second rapid increase in stress. The second plateau region appeared between $16 \%$ and $42 \%$ of engineering strain. This double plateau stress effect can be interpreted by the specific deformation process of the structure (Figure 5b). The cell walls bend under compression, causing the rotation of cell connection points, which characterised the first plateau region. The neighbouring cell walls then came into contact at isolated contact points at half the cell size, contributing to an increase of the structural stiffness (second linear increase of the stress). This was then followed by further bending and yielding of effectively shorter walls, resulting in a slightly stiffer second plateau region. The deformation process ended with complete structure densification and subsequent collapse.

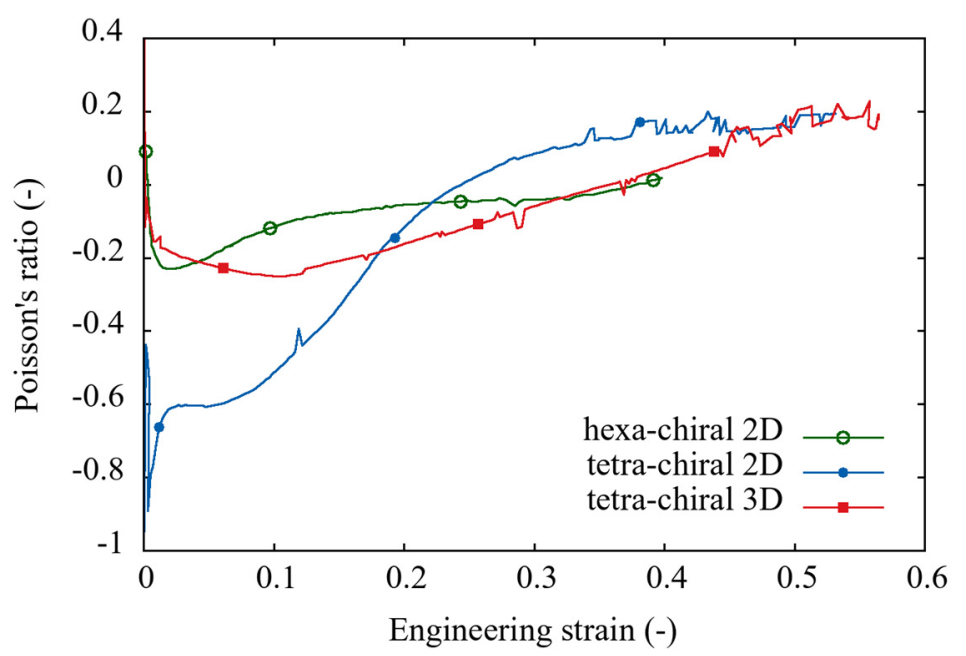

Figure 4. Average quasi-static Poisson's ratio-strain relationships of hexa-chiral 2D, tetra-chiral 2D, and tetra-chiral 3D structure. 
(a)
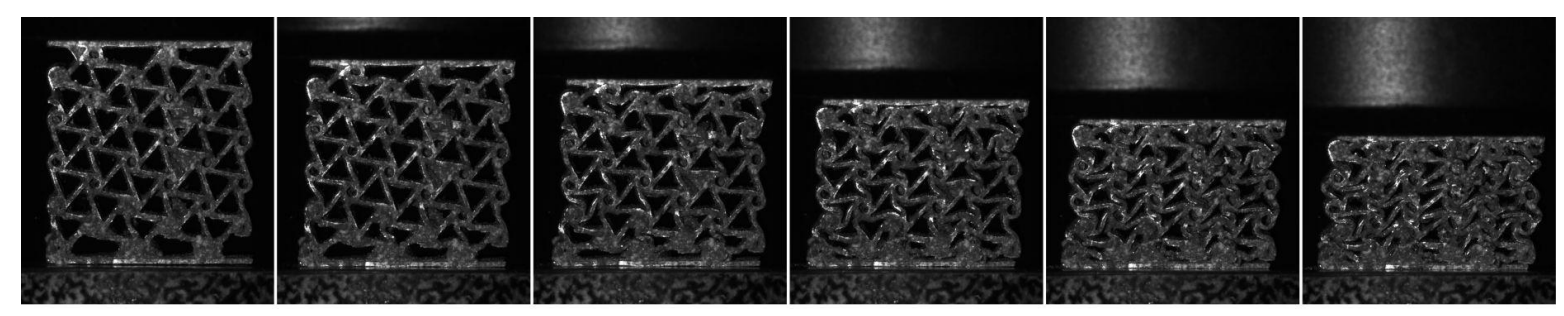

(b)
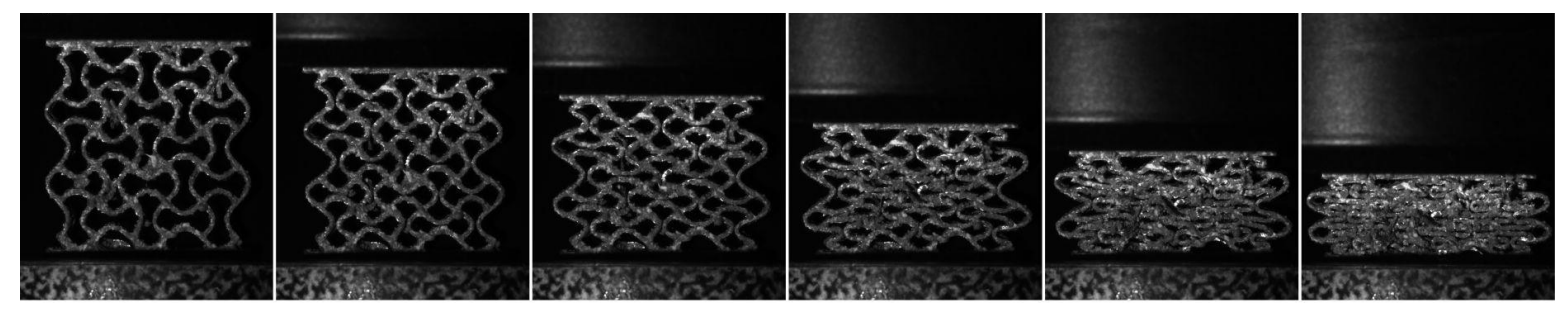

(c)
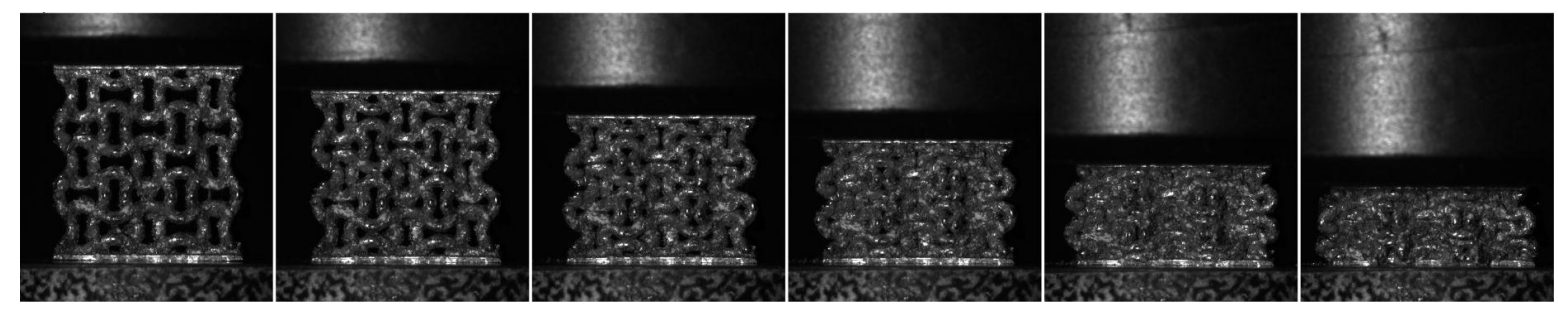

Figure 5. Quasi-static compression deformation sequences of (a) hexa-chiral 2D, (b) tetra-chiral 2D, and (c) tetra-chiral 3D structure by the strain increment of $10 \%$.

The tetra-chiral 2D structure exhibited pronounced auxetic behaviour with measured negative Poisson's ratio of -0.81 at the beginning of the deformation (Figure 4 ). The Poisson's ratio then rapidly increased to -0.61 at $3 \%$ of engineering strain. Then the Poisson's ratio became zero at $24 \%$ of engineering strain and reached 0.19 at the end of the experiment. For the correlation of the plateau regions and the auxetic behaviour, it was found that the auxetic effect of the structure persists through the start of the second plateau region, or until the walls can deform almost freely.

\subsubsection{Tetra-Chiral 3D Structure}

The observed yield stress of the tetra-chiral 3D structure was $35 \mathrm{MPa}$. A short stress plateau region appeared between $3.4 \%$ and $13 \%$ of engineering strain. The maximum negative value of Poisson's ratio of -0.25 was detected at a very early stage of deformation at $10 \%$ of the engineering strain (Figure 4 ). Poisson's value then gradually increased to approximately 0 at $36 \%$ of engineering strain and became positive after that.

\subsection{Impact Testing Results}

The average dynamic engineering stress-strain relationships compared to the quasistatic results together with average engineering strain-rates achieved during dynamic experiments are shown in Figure 6.

\subsubsection{Hexa-Chiral 2D Structure}

Figure 6a shows the dynamic response of the hexa-chiral 2D structure in terms of average engineering stress-strain and strain-rate-strain relationships, as derived from SHPB measurements with strain-gauges. The results at lower impact velocity D1 are the following: the initial yield stress of $86 \mathrm{MPa}$, maximum achieved engineering strain of 
0.22 and strain-rate of approximately $1000 \mathrm{~s}^{-1}$. The higher impact velocity D2 returned the same value of the initial yield stress of $86 \mathrm{MPa}$, a higher achieved maximum strain of 0.3 at the increased strain-rate of $2300 \mathrm{~s}^{-1}$. The results indicate almost no difference between two impact velocities (strain-rates), apart from some difference in maximum achieved engineering strain.
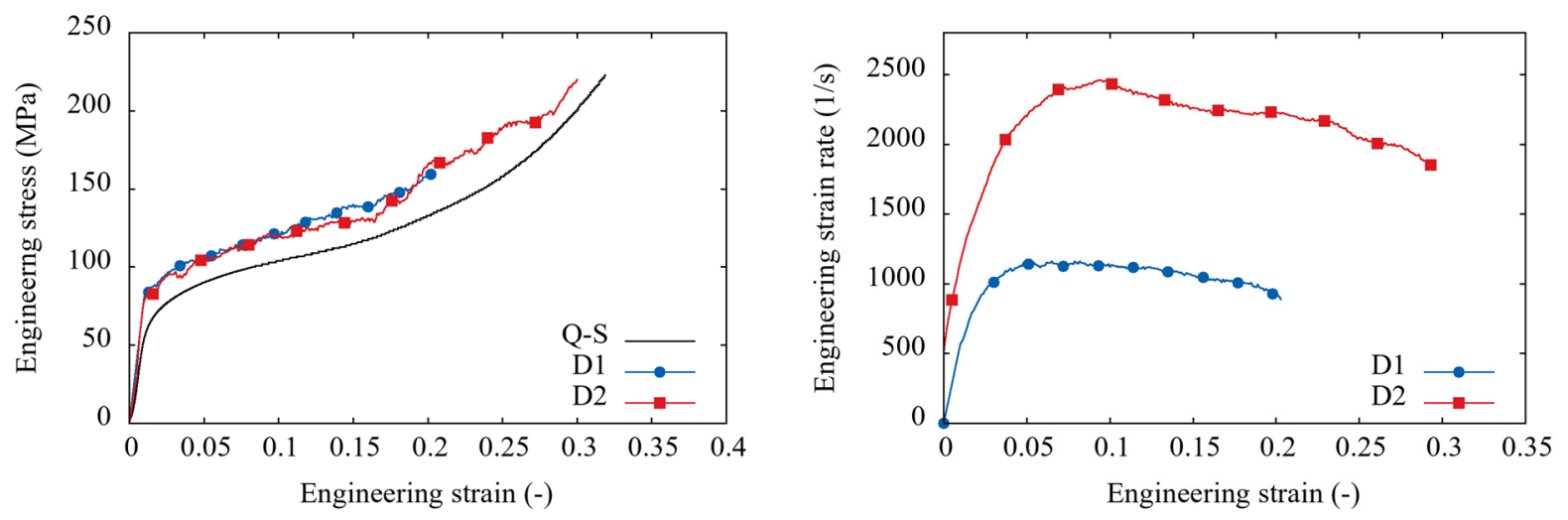

(a)
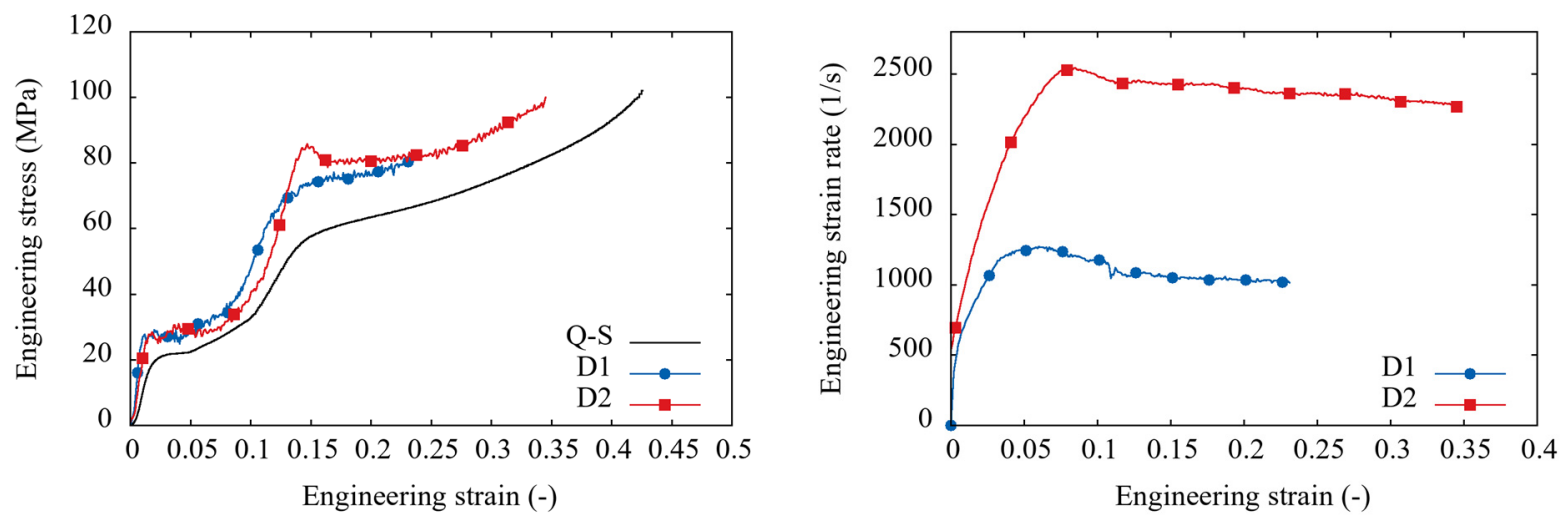

(b)
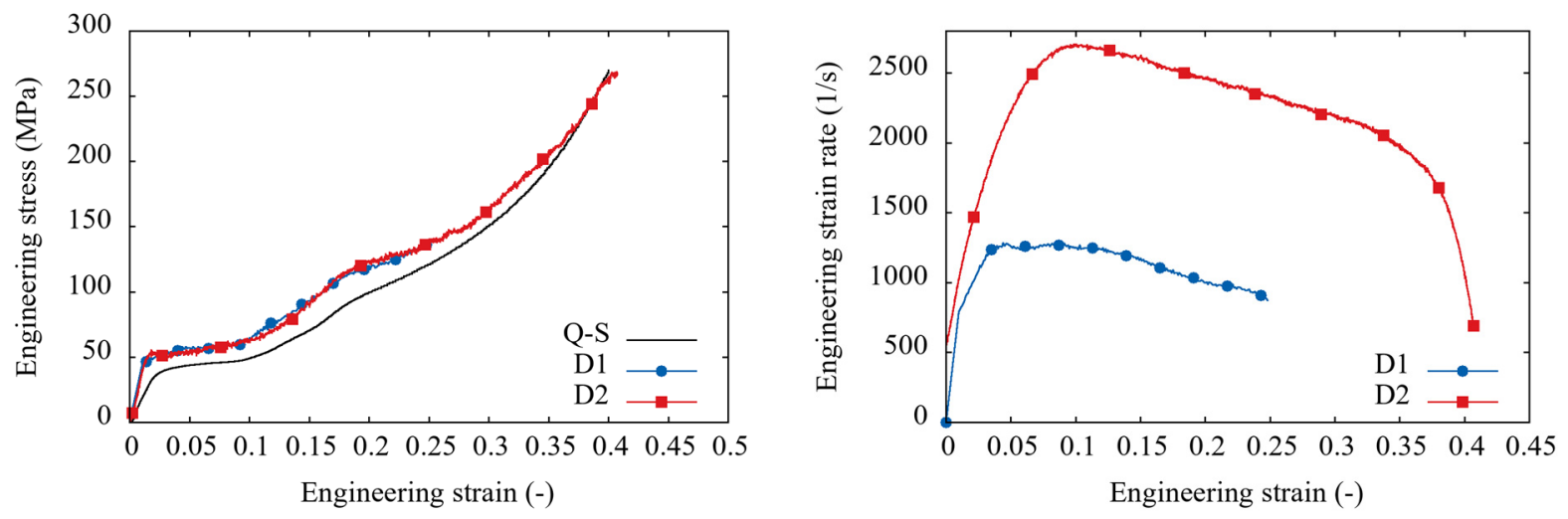

(c)

Figure 6. The average engineering stress-strain and strain-rate-strain relationships at lower (D1) and higher (D2) impact velocity: (a) hexa-chiral 2D, (b) tetra-chiral 2D, and (c) tetra-chiral 3D structure.

The dynamic response of the structure is different from the quasi-static one with clearly identified stress enhancement. The dynamic initial yield stress was higher by approximately $20 \%$ and similar stress increase can be observed during the quasi-plateau 
region. Larger strikers or higher acceleration pressures used in SHPB tests are necessary to achieve a higher deformation rate and higher maximum engineering strain. This was not possible in this study due to limitations of the used SHPB design.

\subsubsection{Tetra-Chiral 2D Structure}

The dynamic response of the tetra-chiral 2D structure is shown in Figure $6 \mathrm{~b}$. The results at lower impact velocity D1 are the following: the initial yield stress of $28.5 \mathrm{MPa}$, maximum engineering strain of 0.25 , and strain-rate of approximately $1000 \mathrm{~s}^{-1}$. A slightly higher yield stress of $30 \mathrm{MPa}$ was observed at higher impact velocity D2 with a maximum engineering strain of 0.35 at a strain-rate of approximately $2400 \mathrm{~s}^{-1}$. The change of loading velocity causes a slightly different transition between double plateau regions. The first plateau region is mostly the same for both loading velocities and occurs between $1.1 \%$ and $6.9 \%$. The second plateau region for lower impact velocity D1 appears between $15.5 \%$ and $20.2 \%$, while it is slightly delayed and more prolonged for the higher impact velocity D2 between $16.2 \%$ and $25.5 \%$ of engineering strain. The prolonged plateau region at a higher strain-rate can be attributed to the higher stress enhancement of the structure in the second deformation phase of the structural cells.

The dynamic results of the structure again show some stress enhancement. The dynamic initial yield stress was higher by approximately $30 \%$ and a similar stress increase can be observed during the quasi-plateau region. Comparing the plateau regions from both deformation regimes, the dynamic plateau regions are flatter and more prolonged than those in the quasi-static regime.

\subsubsection{Tetra-Chiral 3D Structure}

The dynamic response of the tetra-chiral 3D structure is shown in Figure $6 \mathrm{c}$. The results at lower impact velocity D1 are the following: the initial yield stress of $50 \mathrm{MPa}$, maximum engineering strain of 0.25 and a strain-rate of approximately $1100 \mathrm{~s}^{-1}$. Higher impact velocity D2 returned the same initial yield stress of $50 \mathrm{MPa}$ and a maximum engineering strain of 0.41 at a strain-rate of approximately $2400 \mathrm{~s}^{-1}$. The same plateau region occurred between $2.4 \%$ and $8.2 \%$ of engineering strain for both velocities.

The dynamic results of the 3D tetra-chiral structure also show some stress enhancement by approximately $30 \%$ of the initial yield stress and a similar stress increase in the quasi-plateau region.

\subsection{DIC Results}

The DIC method was implemented for the determination of the deformation field, strain field and Poisson's ratio. All the dynamic experiments were analysed by the DIC method. However, the results of only one representative experiment for each structure at lower D1 and higher D2 velocity are presented here. The nodes of the lattice structure were defined as the tracking points. A typical size of the correlation window was $8 \mathrm{px}$ and correlation window offset was $4 \mathrm{px}$. The validity of DIC results was confirmed by comparing the strain-gauges results and calculation of the mean correlation coefficient, which was higher than $96 \%$ in all cases. The typical digital size of the specimen was $130 \times 140$ pixels.

The strain fields were calculated first. Figure 7 shows the evolution of the incremental longitudinal full-field engineering strain in all tested structures during the impact testing. The results in Figure 7 are included for easier interpretation of strain distribution in the cellular structure during impact. In the case of the hexa-chiral 2D structure (Figure 7a) tested at lower impact velocity D1, the first deformation of the structure occurred on the opposite side of the impact (at the transmission bar side), while at the higher impact velocity D2 the first deformation initiated at the impact side (at the incident bar). This indicates a possibility in a change of deformation mechanism between impact velocities D1 and D2 that may start to develop from intermediate to shock. In the case of the 2D tetra-chiral structure, the deformation mechanism was almost identical at both impact velocities. Most 
of the deformation was present or localised in the centre of the samples, while the edges of the samples deformed lastly. A localised deformation in the centre of the samples can be attributed to the higher stiffness of the edges due to the additional positioning plates. A similar deformation mechanism occurred in the tetra-chiral 3D structure. As already observed in the study [15], the difference in strain between the loading and the supporting edge is evident.

(a)
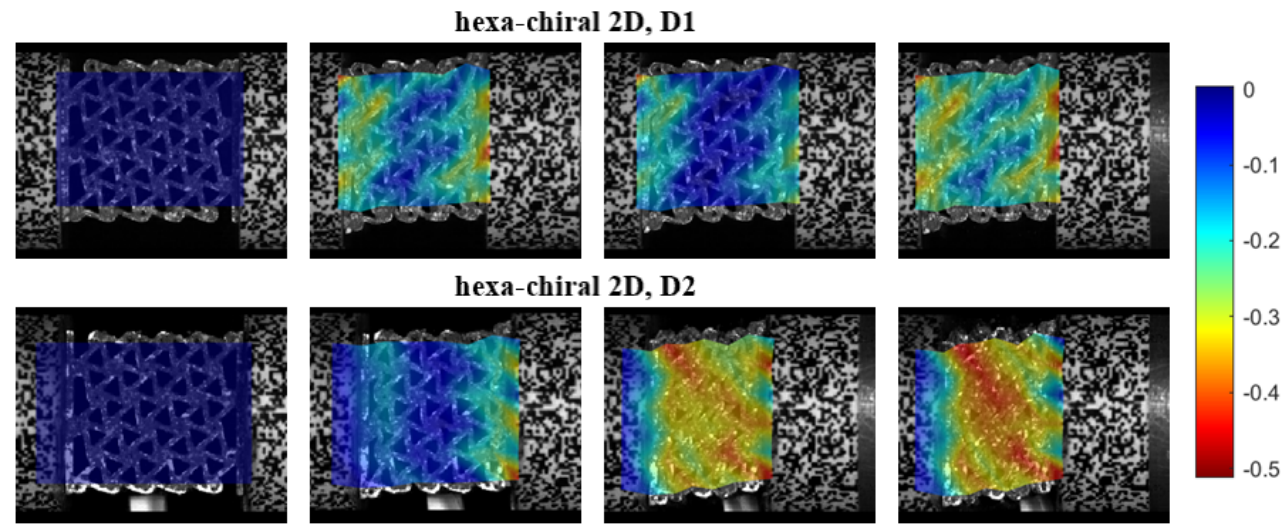

(b)

tetra-chiral 2D, D1
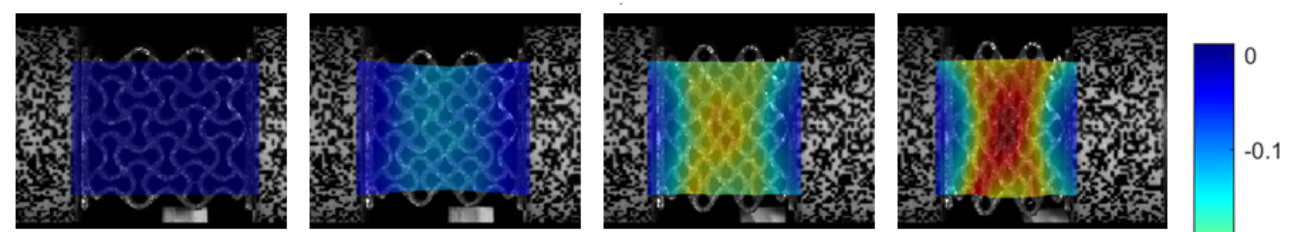

tetra-chiral 2D, D2
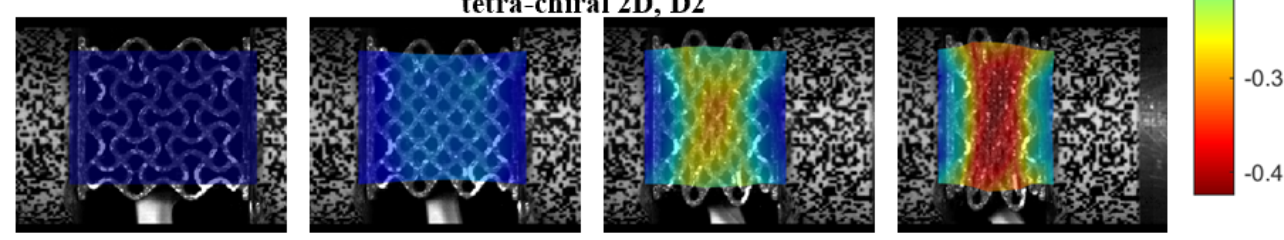

(c)
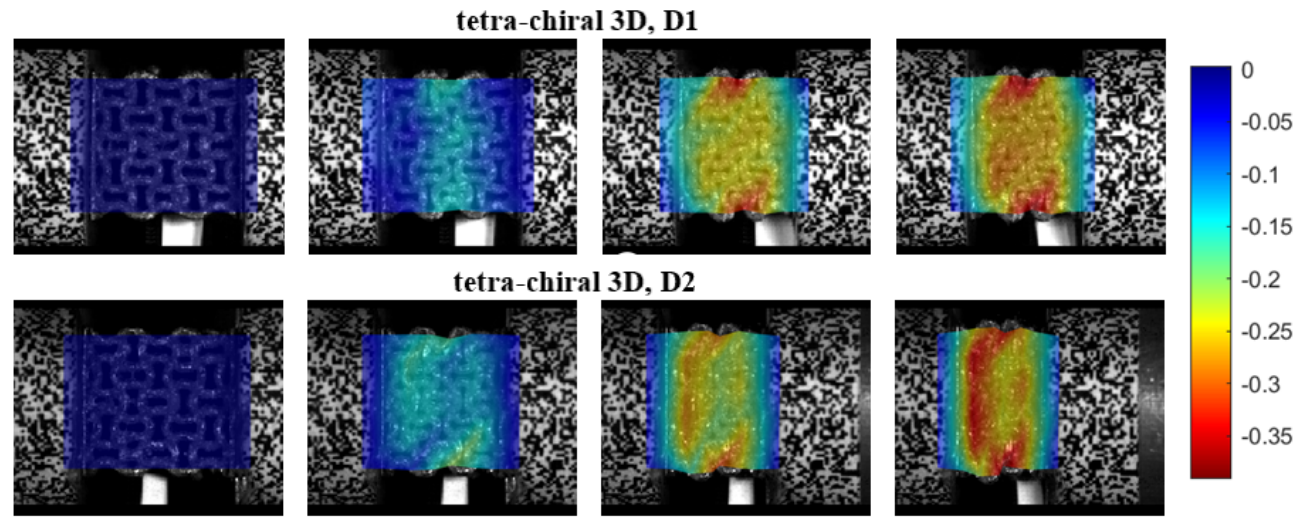

Figure 7. Evolution of full-field longitudinal strain of (a) hexa-chiral 2D, (b) tetra-chiral 2D, and (c) tetra-chiral 3D structure during impact testing at lower (D1) and higher (D2) impact velocity.

A comparison of DIC and measured results in terms of engineering stress-strain relationships at both impact velocities for all analysed structures are shown in Figure 8. The 
DIC strains were obtained at the edges of the specimen while the engineering stress values were always obtained from processing the strain-gauge measurements. The comparison shows an excellent agreement of DIC and measured results for all structures and striker's impact velocities.

D1
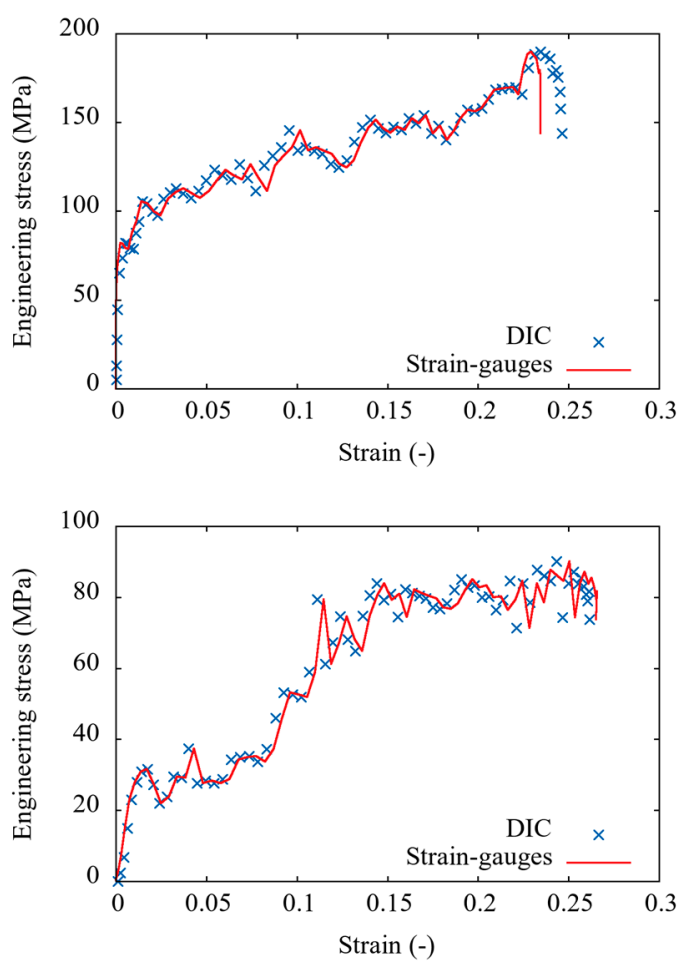

(c)

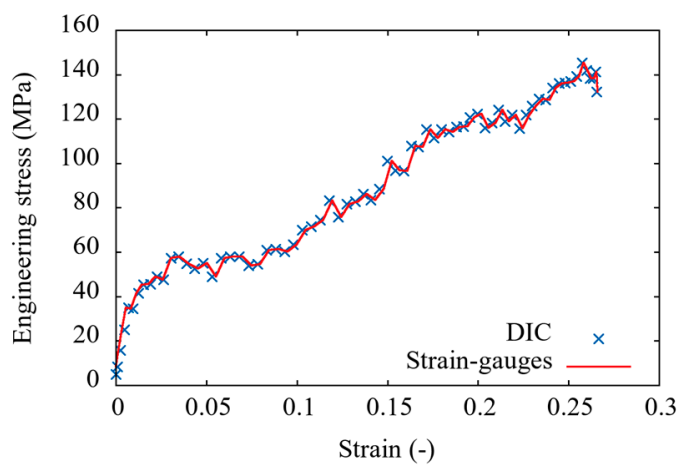

D2
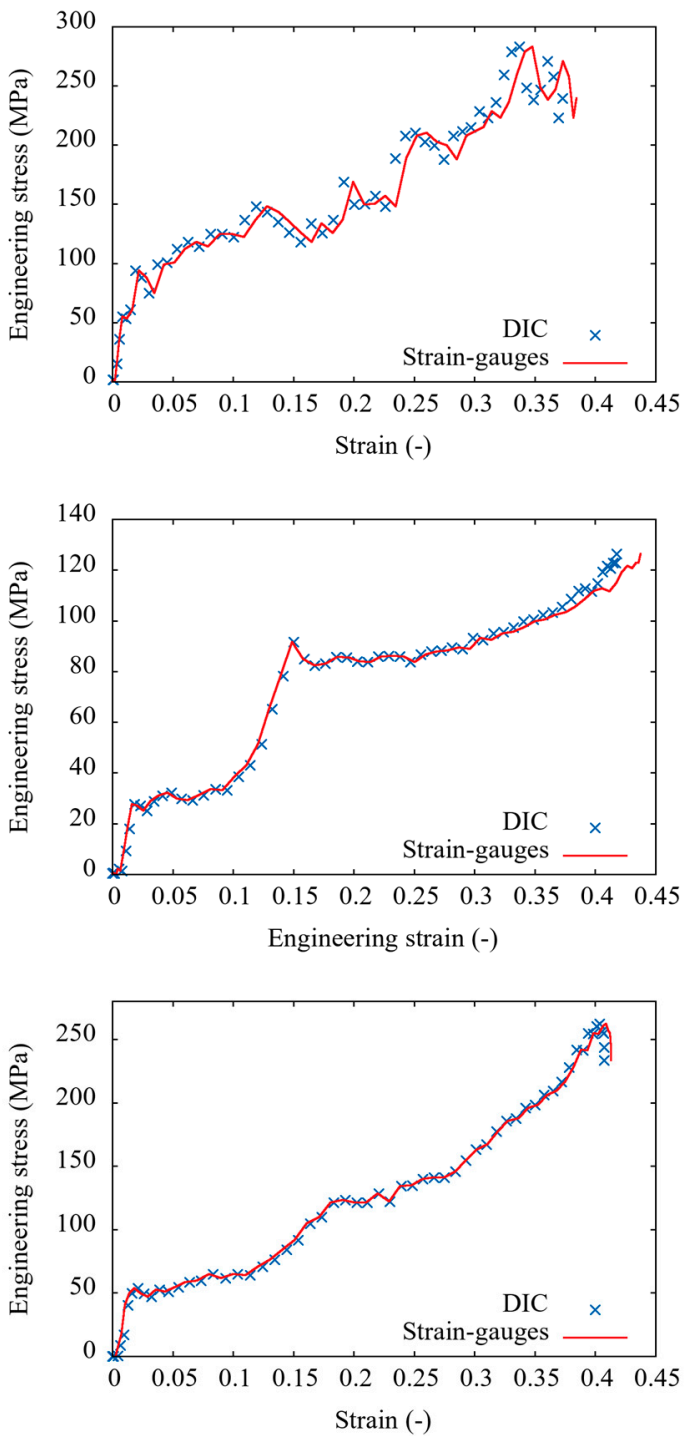

Figure 8. The dynamic engineering stress-strain relationships at lower (D1) and higher (D2) impact velocity, obtained by digital image correlation (DIC) method and strain-gauge measurements: (a) hexa-chiral 2D, (b) tetra-chiral 2D, and (c) tetra-chiral 3D structure.

The variation of the Poisson's ratio during dynamic compression was determined in the next step using the DIC method as the negative value of transverse and axial strain ratio. To determine the Poisson's ratio, it was necessary to define the locations in the structures for the DIC method evaluation [22]. This was crucial, as the deformation was not homogeneous throughout the structure. In the case of Poisson's ratio determination at the outer edges of the structure, the discrepancy between the results was distinct. As a result, the deformation at the extreme edges of the cells was not considered for Poisson's ratio calculations. The variation of the mean Poisson's ratio with a calculated standard deviation for each analysed structure at low D1 and high D2 impact velocity is presented in Figure 9. 


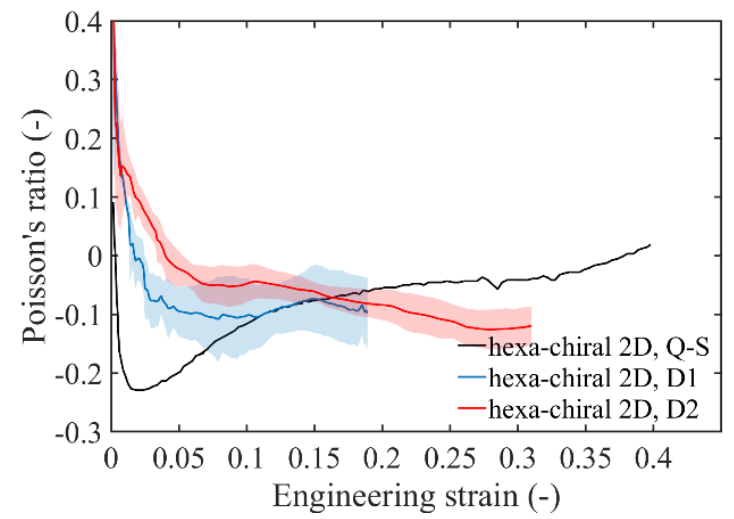

(a)

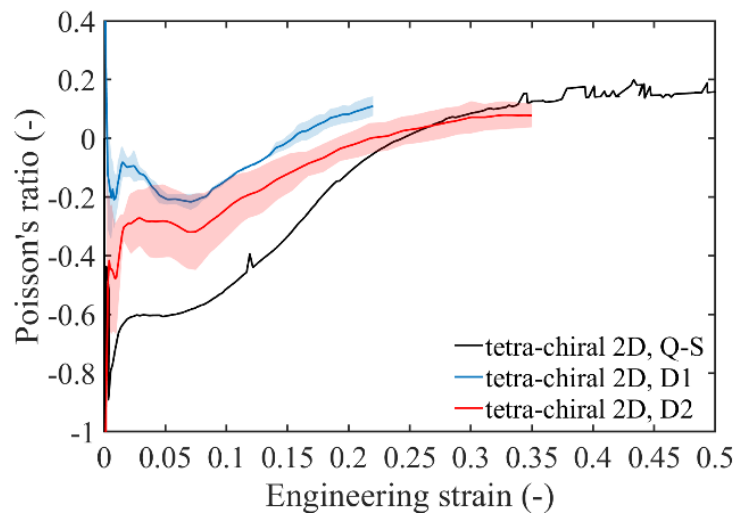

(b)

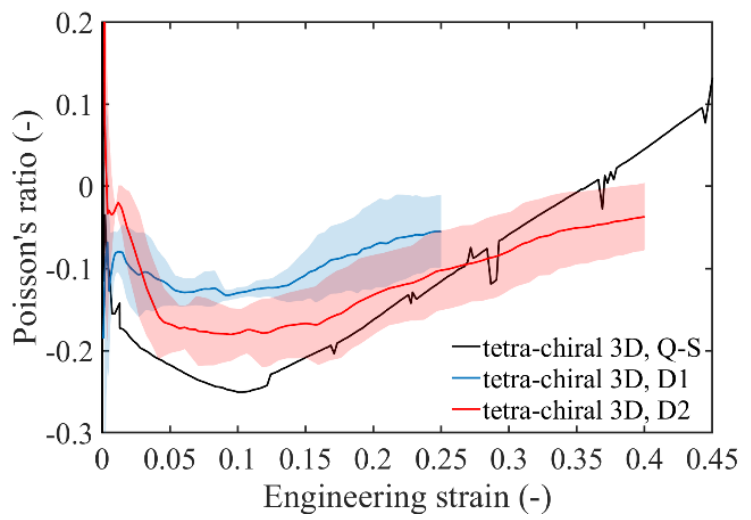

(c)

Figure 9. The Poisson's ratio variation during dynamic testing at impact velocities D1 and D2 for: (a) hexa-chiral 2D, (b) tetra-chiral 2D, and (c) tetra-chiral 3D structure.

The comparison of quasi-static and dynamic Poisson's ratio shows the evident difference. The Poisson's ratio observed in quasi-static testing was distinctively lower than the one observed in dynamic impact experiments due to lower loading velocities and negligible inertia effects. The largest reduction of Poisson's ratio in the dynamically loaded structure at approximately $68 \%$ was observed for the tetra-chiral 2D structure. The reduction of $56 \%$ was observed for the tetra-chiral 3D structure, while the smallest reduction of $47 \%$ was observed for the hexa-chiral 2D structure.

The hexa-chiral 2D structure is auxetic during almost the entire dynamic loading regime, as it is evident from Figure 9a. The Poisson's ratio was positive at the beginning of the loading process at impact velocity D1, followed by a sudden drop to -0.11 at $14 \%$ of engineering strain. The Poisson's ratio the remained almost constant until the end of the experiment. At the impact velocity D2, the observed Poisson's ratio was slightly higher and dropping throughout the whole deformation process, reaching the lowest value of -0.12 at $31 \%$ of engineering strain in the end. Slightly higher values of Poisson's ratio at a higher impact velocity are expected and can be attributed to inertia effects preventing timely auxetic behaviour. No auxetic behaviour is expected at even higher impact velocities, which is yet to be confirmed.

The auxetic behaviour of the tetra-chiral 2D structure can be observed from Figure $9 \mathrm{~b}$. The Poisson's ratio was negative at the beginning of the loading process at the lower impact velocity $\mathrm{D} 1$, followed by a slight drop to -0.23 at $11.2 \%$ of engineering strain, followed by an almost linear increase until becoming positive at $16 \%$ of engineering strain. Then the Poisson's ratio increased to 0.11 at $22 \%$ of engineering strain, indicating non-auxetic behaviour of the structure at the end of the deformation process. The nearly identical shape of the Poisson's ratio variation with surprisingly slightly lower values was observed at the higher impact velocity D2. In the beginning, the observed Poisson's ratio was again 
negative, followed by a slight drop to -0.32 at $7 \%$, followed by a continuous increase and becoming positive after $22 \%$ of engineering strain until the end of the loading process.

The variation of the Poisson's ratio of the tetra-chiral 3D structure is shown in Figure 9c. At the D1 impact velocity, the initial value of the Poisson's ratio was -0.11 , which decreased to -0.13 at $11 \%$ engineering strain and thereafter increased to -0.05 at the end. A similar Poisson's ratio variation with again surprisingly slightly lower values was observed at higher impact velocity D2. At the D2 impact velocity, the Poisson's ratio was positive in the beginning, followed by a quick drop to -0.17 at $5.5 \%$ of engineering strain. The ratio stayed almost constant up to $14 \%$ of engineering strain and then gradually increased to -0.03 in the end.

The results show only slight differences in Poisson's ratio variation at both loading velocities in all three structures. However, tetra-chiral 2D and 3D structures showed rather unusual behaviour of the Poisson's ratio variation with slightly lower values closer to quasi-static behaviour. The lower Poisson's ratio observed at higher impact velocities is curious, and some further testing at higher impact velocities needs to be done to establish the reasons for that.

\section{Conclusions}

Three different chiral (hexa-chiral 2D, tetra-chiral 2D and tetra-chiral 3D) auxetic structures were produced with PBF manufacturing technique from an austenitic stainless steel alloy. All structures were tested under quasi-static and dynamic (at two impact velocities) compression loading conditions. The dynamic test results were obtained by processing the strain histories captured by strain-gauges and DIC evaluation of highspeed digital recording of experiments. From the results of the experiments, the following conclusions can be summarised:

- A stress increase was observed for all tested structures when comparing the quasistatic and dynamic results, indicating the strain-rate dependency of tested auxetic cellular structures. A slight difference in response was observed between results obtained at two dynamic impact velocities. The achievable strain-rates in this study were limited by the design of the used SHPB apparatus. Further experiments conducted at higher and lower strain-rates are required to establish the dynamic strain-rate dependency.

- The characteristic stress plateau region was observed only until the first contacts between the cell walls. The thickness of the struts and cell size significantly influence the behaviour of chiral samples. The cell size and struts thickness were in this study limited by the manufacturing process and testing device. Only short plateau regions were observed for all tested structures due to small cells with thick struts.

- All three structures showed a significant auxetic response in quasi-static and dynamic loading regimes. The highest auxetic effect was observed for the tetra-chiral 2D structure. The auxetic response was strain-rate dependent for all three structures.

- The interestingly different strain-rate dependency of the auxetic structures was shown in previous studies [22], where the global minimum of Poisson's ratio decreased with the increasing strain-rate. In contrast, structures in this study exhibit the most profound auxetic behaviour in the case of quasi-static loading. The diversity of results may be induced by the difference in the porosity of the samples, cell size, and nonlinearities in the structures and due to the dependency of the base materials. Also, the structure may be bending or buckling predominated, which can cause different strain-rate dependencies.

- Due to the localised deformation, the main properties of the auxetic structures must be determined locally $[15,22]$.

- The addition of positioning plates to tested structures contributed to higher cell stiffness at the top and bottom of specimens leading to deformation of samples appearing mostly in the middle of the samples. 
- In the previous numerical study of the Poisson's ratio by the chiral structures [17] the importance of the cell size and amplitude was established. With the magnification of the cell size, the auxetic effect was increased. In the case of this research, the cell size was constricted by the SHPB design. Therefore, the neighbouring cells came into contact in the early stages of deformation. This was also evident in the short plateau region. By making the cell size larger, the structure would deform more freely and achieve an even more profound auxetic response.

- The 2D and 3D tetra-chiral structures showed rather unusual behaviour with the Poisson's ratio variation with slightly lower values closer to quasi-static behaviour. The lower Poisson's ratio observed at higher impact velocities is curious and some further testing at higher impact velocities needs to be done to establish the reasons for that.

Author Contributions: Conceptualisation, A.M., M.V. and Z.R.; software, V.R.; validation, A.M. and T.F; formal analysis, A.M.; investigation, A.M., T.F., J.F., M.N., P.K. and P.Z.; data curation, A.M. and J.F.; writing—original draft preparation, A.M.; writing—review and editing, all authors; visualisation, A.M.; supervision, Z.R., M.V. and O.J.; project administration, O.J. All authors have read and agreed to the published version of the manuscript.

Funding: This research was funded by the Operational Programme Research, Development and Education in the project INAFYM (CZ.02.1.01/0.0/0.0/16_019/0000766) and the Slovenian Research Agency (research programme No. P2-0063 and research project No. J2-8186). Support of the internal project of the Czech Technical University no. SGS20/142/OHK2/2T/16 is acknowledged as well.

Institutional Review Board Statement: Not applicable.

Informed Consent Statement: Informed consent was obtained from all subjects involved in the study.

Data Availability Statement: The data presented in this study are available on request from the corresponding author.

Conflicts of Interest: The authors declare no conflict of interest.

\section{References}

1. Ashby, M.F.; Evans, A.G.; Fleck, N.A.; Gibson, L.J.; Hutchinson, J.W.; Wadley, H.N.G. Metal Foams: A Design Guide; Elsevier Science: Burlington, MA, USA, 2000.

2. Lehmhus, D.; Vesenjak, M.; De Schampheleire, S.; Fiedler, T.; Lehmhus, D.; Vesenjak, M.; De Schampheleire, S.; Fiedler, T. From Stochastic Foam to Designed Structure: Balancing Cost and Performance of Cellular Metals. Materials 2017, 10, 922. [CrossRef]

3. Banhart, J. Manufacture, characterisation and application of cellular metals and metal foams. Prog. Mater. Sci. 2001, 46, 559632. [CrossRef]

4. Evans, K.E. Molecular Network Design. Nature 1991, 353, 124. [CrossRef]

5. Novak, N.; Vesenjak, M.; Ren, Z. Auxetic cellular materials-A review. J. Mech. Eng. 2016, 62, 485-493. [CrossRef]

6. Novak, N.; Hokamoto, K.; Vesenjak, M.; Ren, Z. Mechanical behaviour of auxetic cellular structures built from inverted tetrapods at high strain rates. Int. J. Impact Eng. 2018, 122, 83-90. [CrossRef]

7. Lakes, R. Foam structures with a negative poisson's ratio. Science 1987, 235, 1038-1040. [CrossRef]

8. Grima, J.N.; Gatt, R.; Farrugia, P.-S. On the properties of auxetic meta-tetrachiral structures. Phys. Status Solidi B 2008, 245, 511-520. [CrossRef]

9. Spadoni, A.; Ruzzene, M. Elasto-static micropolar behavior of a chiral auxetic lattice. J. Mech. Phys. Solids 2012, 60, 156-171. [CrossRef]

10. Mousanezhad, D.; Haghpanah, B.; Ghosh, R.; Hamouda, A.M.; Nayeb-Hashemi, H.; Vaziri, A. Elastic properties of chiral, anti-chiral, and hierarchical honeycombs: A simple energy-based approach. Theor. Appl. Mech. Lett. 2016, 6, 81-96. [CrossRef]

11. Simpson, J.; Kazanc1, Z. Crushing investigation of crash boxes filled with honeycomb and re-entrant (auxetic) lattices. Thin-Walled Struct. 2020, 150, 106676. [CrossRef]

12. Mohsenizadeh, S.; Ahmad, Z. Auxeticity effect on crushing characteristics of auxetic foam-filled square tubes under axial loading. Thin-Walled Struct. 2019, 145, 106379. [CrossRef]

13. Mohsenizadeh, S.; Alipour, R.; Shokri Rad, M.; Farokhi Nejad, A.; Ahmad, Z. Crashworthiness assessment of auxetic foam-filled tube under quasi-static axial loading. Mater. Des. 2015, 88, 258-268. [CrossRef]

14. Duarte, I.; Vesenjak, M.; Krstulović-Opala, L. Variation of quasi-static and dynamic compressive properties in a single aluminium foam block. Mater. Sci. Eng. A 2014, 616, 171-182. [CrossRef]

15. Sun, Y.; Li, Q.M. Dynamic compressive behaviour of cellular materials: A review of phenomenon, mechanism and modelling. Int. J. Impact Eng. 2018, 112, 74-115. [CrossRef] 
16. Xue, Y.; Wang, X.; Wang, W.; Zhong, X.; Han, F. Compressive property of Al-based auxetic lattice structures fabricated by 3-D printing combined with investment casting. Mater. Sci. Eng. A 2018, 722, 255-262. [CrossRef]

17. Novak, N.; Starčevič, L.; Vesenjaka, M.; Ren, Z. Blast response study of the sandwich composite panels with 3D chiral auxetic core. Compos. Struct. 2019, 210, 167-178. [CrossRef]

18. Fíla, T.; Zlámal, P.; Jiroušek, O.; Falta, J.; Koudelka, P.; Kytýř, D.; Doktor, T.; Valach, J. Impact Testing of Polymer-filled Auxetics Using Split Hopkinson Pressure Bar. Adv. Eng. Mater. 2017, 19, 1-13. [CrossRef]

19. Chen, W.; Song, B. Split Hopkinson (Kolsky) Bar Design, Testing and Application; Springer: Berlin/Heidelberg, Germany, 2008; Volume 39.

20. Adorna, M.; Zlámal, P.; Fíla, T.; Falta, J.; Felten, M.; Fries, M.; Jung, A. Testing of Hybrid Nickel-Polyurethane Foams At High Strain-Rates Using Hopkinson Bar and Digital Image Correlation. In Proceedings of the 17th Youth Symposium on Experimental Solid Mechanics, YSESM 2018, Prague, Czech Republic, 23 October 2018; pp. 72-76. [CrossRef]

21. Šleichrt, J.; Fíla, T.; Koudelka, P.; Adorna, M.; Falta, J.; Zlámal, P.; Glinz, J.; Neuhäuserová, M.; Doktor, T.; Mauko, A.; et al. Dynamic penetration of cellular solids: Experimental investigation using Hopkinson bar and computed tomography. Mater. Sci. Eng. A 2021, 800. [CrossRef]

22. Fíla, T.; Koudelka, P.; Zlámal, P.; Falta, J.; Adorna, M.; Neuhäuserová, M.; Luksch, J.; Jiroušek, O. Strain Dependency of Poisson's Ratio of SLS Printed Auxetic Lattices Subjected to Quasi-Static and Dynamic Compressive Loading. Adv. Eng. Mater. 2019, 21, 1900204. [CrossRef]

23. Vesenjak, M. Computational Modelling of Cellular Structures under Impact Conditions; University of Maribor: Maribor, Slovenia, 2006.

24. Instron. 3380 Series Universal Testing Systems up to $100 \mathrm{kN}$ (22,500 lbf) Force Capacity. Available online: https:/ / www.instron. us/en-us/products/testing-systems/universal-testing-systems/electromechanical/3300/3380-floor-model (accessed on 14 December 2020).

25. Jankowiak, T.; Rusinek, A.; Lodygowski, T. Validation of the KlepaczkoMalinowski model for friction correction and recommendations on Split Hopkinson Pressure Bar. Finite Elem. Anal. Des. 2011, 47, 1191-1208. [CrossRef]

26. Fíla, T.; Koudelka, P.; Falta, J.; Zlámal, P.; Rada, V.; Adorna, M.; Bronder, S.; Jiroušek, O. Dynamic impact testing of cellular solids and lattice structures: Application of two-sided direct impact Hopkinson bar. Int. J. Impact Eng. 2021, 148, 103767. [CrossRef]

27. Jandejsek, I.; Valach, J.; Vavř́ik, D. Optimization and calibration of digital image correlation method. Exp. Stress Anal. 2010, $121,126$.

28. Adorna, M.; Bronder, S.; Falta, J.; Zlámal, P.; Fíla, T. Evaluation of Hopkinson bar experiments using multiple digital image correlation software tools. In Proceedings of the 17th Youth Symposium on Experimental Solid Mechanics, YSESM 2019, Prague, Czech Republic, 6 December 2019; Volume 25, pp. 1-5.

29. Ding, Y.; Wang, S.; Zheng, Z.; Yang, L.; Yu, J. Dynamic crushing of cellular materials: A unique dynamic stress-strain state curve. Mech. Mater. 2016, 100, 219-231. [CrossRef] 